\title{
Regional variation in skin blood flow response to hypoglycaemia in Type 1 (insulin-dependent) diabetic patients without complications
}

\author{
P.G.Wiles ${ }^{1}$, P.J.Grant ${ }^{1}$, M.H.Stickland ${ }^{1}$, H.G. Dean ${ }^{2}$, J.K. Wales ${ }^{1}$ and J.A. Davies ${ }^{1}$ \\ University Departments of ${ }^{1}$ Medicine and ${ }^{2}$ Pharmacology, General Infirmary, Leeds, UK
}

\begin{abstract}
Summary. Body temperature falls during hypoglycaemia, perhaps as a protective mechanism. To test the hypothesis that the skin blood flow response to hypoglycaemia is specifically designed to facilitate heat loss we studied both nutritional blood flow and arteriovenous shunting of blood in skin during prolonged, controlled hypoglycaemia in man. We studied eight otherwise healthy, male, Type 1 (insulin-dependent) diabetic patients. Under Biostator control blood glucose was clamped at $8.0(7.9-8.9), \mathrm{mmol} / 1$ (median and range) for $30 \mathrm{~min}$, reduced to symptomatic hypoglycaemia, $1.7(1.0-2.6) \mathrm{mmol} / 1$ for $20 \mathrm{~min}$ then raised to $4.9(3.3-6.7)$ $\mathrm{mmol} / \mathrm{l}$. Interdigital skin web blood flow (laser doppler flowmeter, nutritional flow) fell during hypoglycaemia from $3.1(2.2-3.8)$ to $2.4(1.2-2.8)$ volts and remained depressed. In contrast, finger blood flow (venous occlusion plethysmogra-
\end{abstract}

phy, arteriovenous shunt flow) started high at 54.7 (17.4-85.6), remained high at 52.7 (38.1-81.4) during hypoglycaemia but fell sharply to $25.3(4.2-66.2) \mathrm{ml} \cdot \mathrm{min}^{-1}$. $100 \mathrm{ml}^{-1}$ when symptoms were relieved. Plasma adrenaline and vasopressin both rose during hypoglycaemia from 0.4 $(0.05-0.8)$ to $4.5(2.3-20.2) \mathrm{nmol} / 1$ and from $0.5(0.5-3.5)$ to $4.4(2.0-13.9) \mathrm{pg} / \mathrm{ml}$, respectively, and both fell sharply thereafter. Thus, the high skin blood flow observed during hypoglycaemia in man is due to arteriovenous shunting of blood and is consistent with a thermoregulatory mechanism.

Key words: Hypoglycaemia, diabetes, skin blood flow, arteriovenous anastomoses, thermoregulation, vasopressin, adrenaline, laser doppler flowmetry.
Hypoglycaemia in animals and man is accompanied by a fall in body temperature. This fall is associated with neuroglycopoenia [1] and the lowered body temperature is thought to protect the brain from the harmful effects of glucose deprivation [2]. In animals there is a decrease in heat production [3] but in man, heat loss during hypoglycaemia occurs despite an increase in non-shivering heat production [4].

During hypoglycaemia in man limb blood flow is increased overall, despite the obvious increase in sympatho-adrenal tone. It is postulated that this rise in blood flow allows heat to be lost during hypoglycaemia [4], an effect enhanced by increased sweating and depressed shivering. Increased blood flow during hypoglycaemia has been described in the forearm $[5,6]$, both in muscle and skin circulations [7, 8]. Similarly, a rise is seen in hand blood flow, which largely reflects the skin circulation $[4,9]$. Subcutaneous blood flow, in contrast, seems to be reduced during and after hypoglycaemia [10]. Thus, during hypoglycaemia, blood flow increases in muscle and skin but appears to fall in subcutaneous tissues.
Accordingly, we have investigated skin blood flow during hypoglycaemia in diabetic men to re-evaluate the hypothesis that vasodilatation in the skin occurs to promote loss of heat. We have also related changes in skin blood flow to the levels of circulating catecholamines and vasopressin. We measured blood flow continuously during insulin-induced hypoglycaemia in two closely adjacent areas in the skin of the hands, the skin webs between the fingers, where there are few arteriovenous (a-v) anastomoses, and the skin of the fingers, where there are many $a-v$ anastomoses. This enabled us to detect selective changes in skin blood flow, which allows arteriovenous shunting of blood through anastomoses, a process designed to increase heat loss.

\section{Subjects and methods}

\section{Patients}

Eight otherwise healthy, male, Type 1 (insulin-dependent) diabetic patients were studied; mean age 25 years (range 18-34), mean duration of diabetes 11 years (4-18), mean $\mathrm{HbA}_{1 c} 10.0 \%$ (7.8-11.8), mean 


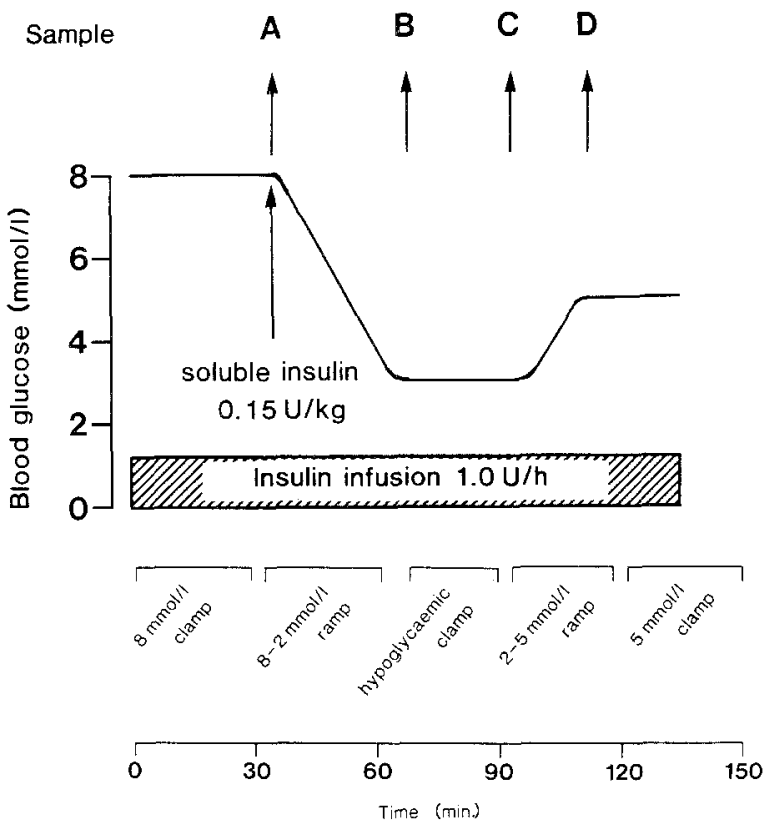

Fig. 1. Schematic representation of the manipulation of blood glucose showing the timing of venous blood sampling for blood glucose, plasma free insulin, plasma adrenaline and plasma vasopressin

body mass index $29.5 \mathrm{~kg}^{2} / \mathrm{cm}(23-37)$ and mean daily insulin dose $0.85 \mathrm{U} / \mathrm{kg}(0.32-1.13)$. All were diagnosed before the age of 30 years and began insulin treatment within the first year of diagnosis. None had autonomic neuropathy, as defined by normal skin flow responses to stimuli such as cough, gasp, noise and mental arithmetic. Patients gave informed consent for the study which was approved by the Leeds West Research Ethics Committee. They arrived for the study having had breakfast and short acting insulin only. None had experienced symptomatic hypoglycaemia in the previous $24 \mathrm{~h}$.

\section{Procedure}

Subjects were studied supine in a room with constant temperature of $24^{\circ} \mathrm{C}$. They were acclimatised to the temperature and surroundings for at least $30 \mathrm{~min}$ during which time intravenous cannulae were inserted into a left antecubital vein and, retrogradely, into a left forearm vein. The former was used for infusion of $10 \%$ dextrose solution, the latter for a double lumen catheter attached to a Biostator (Miles, Slough, UK) and kept open with a slow infusion of heparinised saline $(50000 \mathrm{U} / 1)$. Venous blood was withdrawn continuously at $2 \mathrm{ml} / \mathrm{h}$ and blood glucose estimated every minute. The Biostator was calibrated against a Yellow Springs Analyser (Yellow Springs Instruments, Yellow Springs, Ohio, USA) and blood glucose maintained using a modified microcomputer controlled clamp technique [11].

\section{Blood flow measurements}

Finger and forearm blood flow were measured continuously by ECG-triggered, venous-occlusion plethysmography (Periflow, Jansen, Brussels, Belgium) using mercury-in-rubber strain gauges measuring blood flow in terms of $\mathrm{ml} \cdot \mathrm{min}^{-1} \cdot 100 \mathrm{ml}^{-1}$. Hand interdigital skin blood flow was measured continuously using a laser-doppler flow meter (Periflux, Perimed, Stockholm, Sweden) measuring skin blood flow arbitrarily in volts. The skin of the finger is rich in arteriovenous anastomoses ( $\mathrm{a}-\mathrm{v}$ shunts) and therefore finger blood flow represents flow through $\mathrm{a}-\mathrm{v}$ shunts as well as nutritional capillaries in skin. In contrast, skin of the web between the fingers is relatively devoid of a-v shunts and therefore interdigital skin blood flow predominantly reflects flow through capillaries in skin. Arteriovenous anastomoses are found in most skin areas but are particularly dense in the skin of fingers, palms, toes and soles whereas they are virtually absent on the dorsal surface of both hands and feet [12]. Forearm blood flow represents blood flow through both muscle and skin vascular beds. These techniques have been described in detail elsewhere [13] and both provide highly sensitive continuous measurements of peripheral blood flow. Facial skin temperature was measured at 5 -min intervals by an electronic thermometer (Comark, Rustington, W. Sussex, UK) with the thermocouple attached to the right cheek using adhesive pads and micropore tape. Heart rate was recorded at 5-min intervals from the ECG monitor. Blood pressure was not measured because of the undesirable effect of repeated inflation of a sphygmomanometer cuff on peripheral blood flow.

\section{Blood glucose control}

Blood glucose was clamped at $8 \mathrm{mmol} / 1$ for $30 \mathrm{~min}$ by constant infusion of Actrapid (Novo, Copenhagen, Denmark) insulin at $1 \mathrm{U} / \mathrm{h}$ and variable infusion of $10 \%$ dextrose. This level was chosen because it allowed more rapid stabilisation of blood glucose at a level close to patients' blood glucose on arrival using a minimum of dextrose infusion. Blood glucose was reduced until symptoms of hypoglycaemia were apparent by giving a bolus injection of $0.15 \mathrm{U} / \mathrm{kg}$ Actrapid insulin and by reducing the amount of dextrose infusion. Blood glucose was then held steady for 20 min to maintain symptomatic hypoglycaemia. At the end of this period, dextrose was infused to take blood glucose back to $5 \mathrm{mmol} / 1$, where it was held for $30 \mathrm{~min}$. This level was chosen to keep the volume of dextrose infusion to a minimum and reduce any effect of the dextrose infusion on peripheral blood flow. Blood flow was measured continuously so as to be able to identify the exact time of any changes in relation to blood glucose, insulin injection and symptoms. Venous blood samples were taken at the end of the $8 \mathrm{mmol} / \mathrm{l}$ blood glucose clamp (sample A), at the onset of hypoglycaemia (sample B), after $20 \mathrm{~min}$ hypoglycaemia (sample C) and when the blood glucose had reached $5 \mathrm{mmol} / \mathrm{l}$ (sample D, see Fig. 1). Samples were analysed for blood glucose, plasma insulin by radioimmunoassay (R.I.A., Newcastle, UK), plasma vasopressin by a charcoal separation, single antibody radioimmunoassay [14] and plasma adrenaline by a radioenzymatic method [15].

\section{Statistical analysis}

Statistical analyses were by Wilcoxon's rank sum test. Results are expressed as median and range. Continuous blood flow measurements are illustrated conventionally as mean and standard error of the mean (SEM). Blood flow data given in the text are the average of 5 min continuous measurements taken at the time of blood sampling as detailed above.

\section{Results}

All subjects developed symptoms and signs of hypoglycaemia which persisted for $20 \mathrm{~min}$. All showed facial pallor, sweating and experienced their typical symptoms of hypoglycaemia. None lost consciousness. All developed shivering as hypoglycaemia was relieved.

\section{Heart rate}

In all patients a rise in heart rate preceded symptoms of hypoglycaemia by 1-2 min. Heart rate rose by 20 $(10-32)$ beats/min (median and range) $(p<0.01)$, but this rise was not sustained despite continuing symptoms (see Table 1). 
Table 1. Changes in blood glucose, plasma free insulin, plasma adrenaline, plasma vasopressin, heart rate and facial temperature during controlled insulin-induced hypoglycaemia in eight otherwise healthy, Type 1 (insulin-dependent) diabetic male patients. Samples were taken before bolus insulin injection (A), at onset of hypogly caemia (B), after 20 min hypoglycaemia (C) and after return to normoglycaemia (D). Results are given as median and range. ${ }^{a} p<0.01$ compared to sample A

\begin{tabular}{|c|c|c|c|c|}
\hline & A & B & $\mathrm{C}$ & $\mathrm{D}$ \\
\hline $\begin{array}{l}\text { Blood glucose } \\
(\mathrm{mmol} / 1)\end{array}$ & $\begin{array}{l}8.0 \\
(7.9-8.9)\end{array}$ & $\begin{array}{l}1.7^{\mathrm{a}} \\
(1.0-2.6)\end{array}$ & $\begin{array}{l}1.7^{\mathrm{a}} \\
(1.1-3.1)\end{array}$ & $\begin{array}{l}4.9^{\mathrm{a}} \\
(3.3-6.7)\end{array}$ \\
\hline $\begin{array}{l}\text { Plasma insulin } \\
(\mathrm{mU} / \mathrm{l})\end{array}$ & $\begin{array}{l}23 \\
(10-36)\end{array}$ & $\begin{array}{l}114^{a} \\
(60-200)\end{array}$ & $\begin{array}{l}52^{\mathrm{a}} \\
(23-100)\end{array}$ & $\begin{array}{l}30 \\
(15-73)\end{array}$ \\
\hline $\begin{array}{l}\text { Plasma } \\
\text { adrenaline } \\
(\mathrm{nmol} / \mathrm{l})\end{array}$ & $\begin{array}{l}0.4 \\
(0.05-0.8)\end{array}$ & $\begin{array}{l}2.9^{\mathrm{a}} \\
(0.8-16.9)\end{array}$ & $\begin{array}{l}4.5^{\mathrm{a}} \\
(2.3-20.2)\end{array}$ & $\begin{array}{l}0.9 \\
(0.6-2.0)\end{array}$ \\
\hline $\begin{array}{l}\text { Plasma } \\
\text { vasopressin } \\
(\mathrm{pg} / \mathrm{ml})\end{array}$ & $\begin{array}{l}0.5 \\
(0.5-3.5)\end{array}$ & $\begin{array}{l}2.2 \\
(1.0-5.6)\end{array}$ & $\begin{array}{l}4.4^{\mathrm{a}} \\
(2.0-13.9)\end{array}$ & $\begin{array}{l}0.5 \\
(0.5-2.2)\end{array}$ \\
\hline $\begin{array}{l}\text { Heart rate } \\
\text { (beats } / \mathrm{min} \text { ) }\end{array}$ & $\begin{array}{l}70 \\
(54-92)\end{array}$ & $\begin{array}{l}88^{a} \\
(80-124)\end{array}$ & $\begin{array}{l}75 \\
(60-102)\end{array}$ & $\begin{array}{l}67 \\
(54-90)\end{array}$ \\
\hline $\begin{array}{l}\text { Facial } \\
\text { temperature } \\
\left({ }^{\circ} \mathrm{C}\right)\end{array}$ & $\begin{array}{l}35.5 \\
(35.1-36.4)\end{array}$ & $\begin{array}{l}35.3 \\
(34.8-35.9)\end{array}$ & $\begin{array}{l}35.0^{\mathrm{a}} \\
(34.3-35.9)\end{array}$ & $\begin{array}{l}34.6^{\mathrm{a}} \\
(33.2-35.6)\end{array}$ \\
\hline
\end{tabular}

\section{Blood glucose and insulin}

Blood glucose levels confirmed biochemical hypoglycaemia falling to $1.7(1.0-2.6) \mathrm{mmol} / 1$ and remaining low for $20 \mathrm{~min}$. Plasma insulin levels rose to 114 $(60-200) \mathrm{mU} / 1$ at the onset of hypoglycaemia but fell to starting levels thereafter (see Table 1). There was no correlation between steady state insulin levels during the run-in period and blood flow measurements. Furthermore, all blood flow changes were coincident with changes in symptoms of hypoglycaemia and not continously variable with changes in blood glucose, nor was there any increase associated with the bolus insulin injection (see Fig. 2).

\section{Plasma adrenaline and vasopressin}

In all subjects both adrenaline and vasopressin rose at the onset and continued to rise during hypoglycaemia, falling towards pre-stress levels thereafter (Table 1). Plasma adrenaline rose by $4.1(2.0-20.3)$ to 4.5 $(2.3-20.2) \mathrm{nmol} / 1(p<0.01)$ during hypoglycaemia, returning towards baseline levels with normal blood glucose. Similarly plasma vasopressin rose by 3.9 $(1.5-10.4)$ to $4.4(2.0-13.9) \mathrm{pg} / \mathrm{ml}(p<0.01)$ during hypoglycaemia, falling back to baseline thereafter. Plasma vasopressin levels during hypoglycaemia correlated with finger blood flow (see below) but there was no other significant correlation between blood flow and plasma hormone levels.

\section{Facial temperature}

Facial temperature fell slowly during, and continued to fall after, hypoglycaemia (Table 1). Temperature was
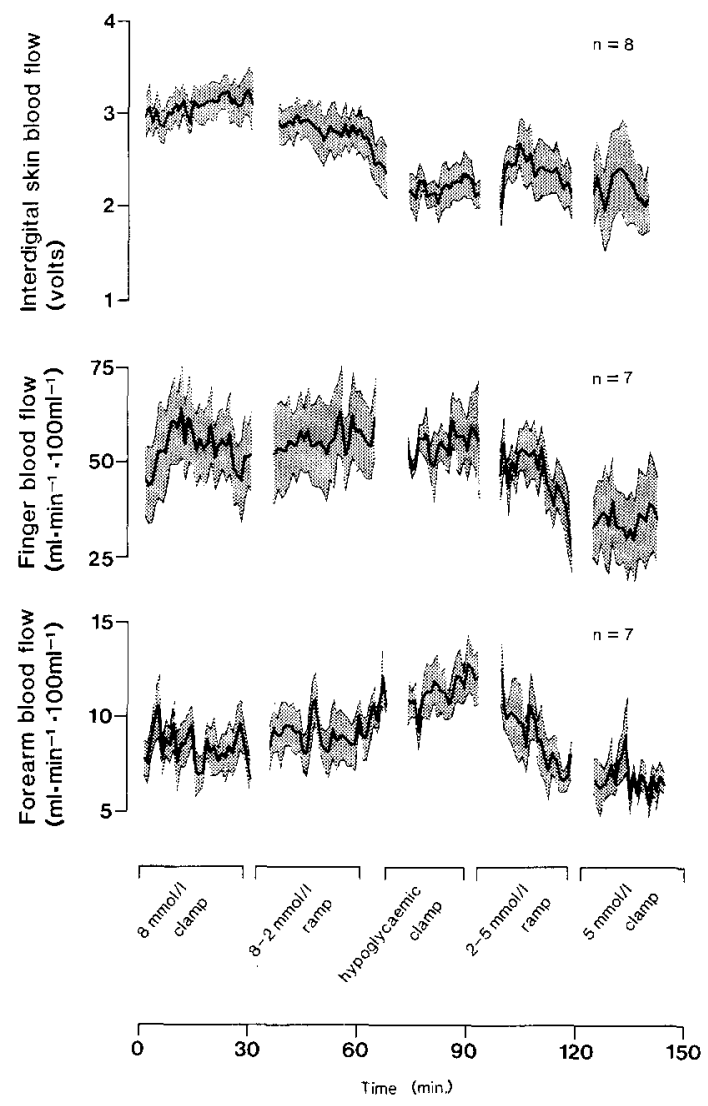

Fig. 2. Changes in hand interdigital skin blood flow (measured by laser doppler flowmeter, upper panel), finger and forearm blood flow (measured by venous occlusion plethysmography, middle and lower panel) before, during and after controlled hypoglycaemic clamp. Results are means \pm SEM

constant at $35.5(35.1-36.4)^{\circ} \mathrm{C}$ before hypoglycaemia and then fell steadily to $34.6(33.2-35.6)^{\circ} \mathrm{C}$ by the end of the study. Despite this relatively small fall in temperature all subjects showed profound facial pallor during hypoglycaemia.

\section{Interdigital skin blood flow}

Blood flow in the skin of the finger web fell during hypoglycaemia, started to fall before the onset of symptoms but coincidentially with the rise in heart rate, and continued to fall slightly after blood glucose was restored to normal (Fig.2). Blood flow fell from 3.1 $(2.2-3.8)$ to $2.4(1.2-2.8)$ volts $(p<0.01)$ and remained low at $2.2(0.9-4.5)$ volts thereafter.

\section{Finger blood flow}

In contrast, finger blood flow, representing skin blood flow predominantly through arteriovenous shunts, remained high during hypoglycaemia but fell sharply with restoration of normoglycaemia (Fig.2). Finger blood flow started high at 54.7 (17.4-85.6), reflecting the high ambient temperature, remained high at 52.7 (38.1-81.4) during hypoglycaemia but fell to 25.3 
$(4.2-66.2) \mathrm{ml} \cdot \mathrm{min}^{-1} \cdot 100 \mathrm{ml}^{-1}(p<0.01)$ when symptoms were relieved. Finger blood flow during hypoglycaemia was correlated with peak plasma vasopressin levels $(r=0.828, t=3.31, p=0.021)$.

\section{Forearm blood flow}

Forearm blood flow, representing flow through muscle as well as skin, rose during hypoglycaemia but also fell to below pre-stress levels thereafter (Fig. 2). Blood flow started at $8.3(5.4-12.4)$ rose to $12.0(7.8-14.4)(p<$ $0.05)$ with hypoglycaemia and fell to $6.4(4.5-10.7)$ $\mathrm{ml} \cdot \mathrm{min}^{-1} \cdot 100 \mathrm{ml}^{-1}(p<0.02)$ with normoglycaemia.

\section{Discussion}

We have found that finger blood flow (representing total skin blood flow, i.e. capillary and a-v shunt flow) remains high during hypoglycaemia, whereas interdigital skin blood flow (representing capillary blood flow) falls. This suggests that there is vasoconstriction in the nutritional capillary bed but, since total skin blood flow remains high, there must be continued arteriovenous shunting of blood in the skin. These findings support the hypothesis that during hypoglycaemia skin blood flow is altered selectively to facilitate heat loss and, on recovery to normoglycaemia, falls to conserve heat, allowing core temperature to return to normal.

Body temperature falls during hypoglycaemia. This phenomenon was noted in 1923 [16] and has been confirmed by many studies in both animals and man. It is specifically related to neuroglycopoenia [1] and is thought to be a protective mechanism, akin to hibernation [2]. Gale and colleagues [4] suggested that an increase in skin blood flow during hypoglycaemia, as described by previous workers $[8,9]$, would be a means of losing heat to facilitate this fall in core temperature and would be enhanced by increased sweating and suppression of shivering. Arteriovenous anastomotic shunts are large calibre channels bypassing the capillary circulation and controlled by muscular glomus bodies $[12,17]$. These shunts allow high volume flow through the skin, allowing rapid delivery of heat and facilitating heat loss from the skin. If the high skin blood flow observed during hypoglycaemia were to be part of a thermoregulatory mechanism designed to lose body heat, blood flow should be preferentially directed to areas rich in $a-v$ shunts. We have found this to be the case among these diabetic men without autonomic neuropathy and conclude that a persistently high flow rate through arteriovenous shunting in the skin during hypoglycaemia is a thermoregulatory mechanism for lowering body temperature.

Mechanisms for this continued arteriovenous shunting are unclear. Limb vasodilatation during hy- poglycaemia occurs in the absence of an adrenaline response [6] but is abolished by anatomical or pharmacological sympathectomy [18] and by $\beta$-blockade [19]. Indeed, in the sympathectomised limb hypoglycaemia induces vasoconstriction [9], presumably related to the unopposed action of increased circulating adrenaline. The vasoconstriction we observed in skin capillary blood flow (interdigital skin blood flow, Fig. 2) could, similarly, be mediated by circulating adrenaline. However, there must be some central mechanism which overrides the otherwise high sympatho-adrenal tone to relax the arteriovenous anastomoses and allow an increase in shunting of blood within the skin. Consistent with this hypothesis is that inhibition of sympathetic vasoconstrictor signals together with a strong increase in sudomotor impulses have been described during hypoglycaemia in normal subjects [2], the authors suggesting that neurally mediated thermoregulatory adjustment contributes to heat loss during hypoglycaemia. Circulating vasopressin as well as catecholamines rise during hypoglycaemia [21]. Infusion of arginine vasopressin (aVP) into man produces peripheral vascular changes similar to those we have observed during hypoglycaemia, i.e. high finger blood flow, lowered interdigital blood flow, profound facial pallor, reduced facial temperature and increased forearm blood flow [13]. Furthermore, in this study, finger blood flow during hypoglycaemia was positively correlated with peak plasma aVP levels. Increased circulating aVP levels might therefore be responsible for the facial pallor of hypoglycaemia and, following relaxation of sympathetic tone [20], could contribute to peripheral vasomotor control.

Thus, these results suggest that the high skin blood flow observed during hypoglycaemia, at least in diabetic man, is due to undiminished arteriovenous shunting of blood and, together with the differential effect on sympathetic activity in skin nerves [20], is consistent with a thermoregulatory mechanism. In contrast, capillary blood flow is reduced during and after hypoglycaemia. This differential effect within the skin circulation might account for the observation that during hypoglycaemia absorption of subcutaneously injected ${ }^{133} \mathrm{Xe}$ (a small molecule absorbed by diffusion) occurs more rapidly than does absorption of insulin, a larger molecule requiring active transfer [22]. If absorption of insulin depends upon blood flow in the capillary circulation, which is reduced by hypoglycaemia, our findings could have implications for insulin-taking diabetic patients. The resulting poor absorption of subcutaneous insulin might, at least in part, explain the metabolic instability consequent upon episodes of hypoglycaemia [10].

Acknowledgements. We are grateful to Dr. R. Jones for help with computation of results and Mrs. M.E.Smith for secretarial assistance. 


\section{References}

1. Freinkel N, Metzger BE, Harris E, Robinson S, Mager M (1972) The hypothermia of hypoglycaemia: studies with 2-deoxy-D-glucose in normal human subjects and mice. N Engl J Med 287: 841-845

2. Gellhorn $E$ (1938) Effects of hypoglycaemia and anoxia on the central nervous system: a basis for a rational therapy of schizophrenia. Arch Neurol Phychiatry 40: 125-146

3. Molnar GW, Read RC (1974) Hypoglycaemia and body temperature. J Am Med Assoc 227: 916-921

4. Gale EAM, Bennett T, Green JH, Macdonald IA (1981) Hypoglycaemia, hypothermia and shivering in man. Clin Sci 61: 463-469

5. Abramson DL, Schkloven N, Margolis NM, Mirsky IA (1939) Influence of massive doses of insulin on peripheral blood flow in man. Am J Physiol 128: 124-132

6. French ED, Kilpatrick $\mathrm{R}$ (1955) The role of adrenaline in hypoglycaemic reactions in man. Clin Sci 14: 639-651

7. Allwood MJ, Birchall I, Staffurth JS (1958) Circulatory changes in the forearm during insulin hypoglycaemia studied by regional ${ }^{24} \mathrm{Na}$ clearance and by plethysmography. J Physiol 143: 332-342

8. Allwood MJ, Hensel H, Papenberg J (1959) Muscle and skin blood flow in the human forearm during insulin hypoglycaemia. J Physiol 147: 269-273

9. Middleton WG, French EB (1974) Studies of the peripheral vasodilator response to acute insulin-induced hypoglycaemia in man. Clin Sci Mol Med 47: 461-470

10. Hilsted J, Madsbad S, Sestoft L (1982) Subcutaneous blood flow during insulin-induced hypoglycaemia: studies in juvenile diabetics with and without autonomic neuropathy and in normal subjects. Clin Physiol 2: 323-332

11. De Fronzo RA, Tobin JP, Andres R (1979) Glucose clamp technique. A method for quantifying insulin secretion and resistance. Am J Physiol 237: E214-233

12. Popoff NW (1934) The digital vascular system with reference to the state of glomus in inflammation, arteriosclerotic gangrene, diabetic gangrene, thromboangitis obliterans and supernumerary digits in man. Arch Pathol 18:295-330
13. Wiles PG, Grant PJ, Davies JA (1986) The differential effect of arginine vasopressin on skin blood flow in man. Clin Sci 71: 633-638

14. Thomas TH, Lee MR (1976) The specificity of antisera for the radioimmunoassay of arginine vasopressin in human plasma and urine during water loading. Clin Sci Mol Med 51: 525-536

15. Da Prada M, Zucher G (1981) Simultaneous radioenzymatic determination of plasma and tissue adrenaline, noradrenaline and dopamine within the fentamole range. Life Sci 19: 1161-1174

16. Dudley HW, Laidlaw PP, Trevan JW, Brock EM (1923) The effect of insulin on the respiratory exchange. J Physiol 57:47

17. Ryan TJ (1973) Structure and shape of blood vessels of skin. In: Jarret A (ed) The Physiology and Pathophysiology of Skin, vol 2. Academic Press, New York, pp 612-619

18. Allwood MJ, Ginsberg J, Paton A (1957) The effect of insulin hypoglycaemia on blood flow in intact and sympathectomised extremities in man. J Physiol 139: 97-107

19. Macdonald IA, Bennett T, Gale EAM, Green JH, Walford S (1982) The effect of propranolol or metoprolol on thermoregulation during insulin-induced hypoglycaemia in man. Clin Sci 63: 301-310

20. Berne C, Fagius J (1986) Skin nerve sympathetic activity during insulin-induced hypoglycaemia. Diabetologia 29: 855-860

21. Baylis PH, Zerbe RL, Robertson GL (1981) Arginine vasopressin response to insulin induced hypoglycaemia in man. $\mathbf{J}$ Clin Endocrinol Metab 53: 935-940

22. Linde B, Fernquist E, Gunnarsson R (1986) Depression of insulin absorption by hypoglycaemia. Diabetologia 29:565A

Received: 8 August 1987

and in revised form: 27 November 1987

Dr. P.G. Wiles

University Department of Medicine

General Infirmary

Leeds LS1 3EX

UK 